\title{
"Endometriosis": A neuro-etiologic framework for its causes and consequences
}

\author{
YANG Bing Xin, GU Ni Hao, JIANG Ji Lan, XU Hong*, ZHANG Hui Juan and Quinn MJ* \\ Departments of Gynaecology \& Pathology, Shanghai Jiao Tong University, China
}

\begin{abstract}
In recent decades the gynecologic response to "endometriosis" has been to excise, or ablate, its deposits with high rates of recurrent pain. However, there is growing dissatisfaction with surgical outcomes, and, a chorus of clinicians recently called for an improved clinical approach. They want to enhance the use of "clinical" diagnosis to improve "delays in diagnosis", "bring about more rapid relief", "limit disease progression" and "prevent sequelae". This ambitious agenda is not just a "call to action"; it implies a fundamental shift in approach - though the details of that "shift" were not detailed in the article.

In the "autonomic denervation" view of the pathogenesis of "endometriosis", there are two key pathogenic principles that govern its laparoscopic appearances. Firstly, injuries to uterotubal nerves result in uterotubal dysmotility and retrograde menstruation with, ectopic endometrium deposited in the pelvis. "Difficult", first labors, straining on the toilet and gynecologic surgery cause the initial pelvic neural injuries. Secondly, ectopic endometrium attaches to anatomic sites of tissue injury e.g. injured uterosacral ligaments, injured peritoneal surfaces, hip replacements, etc if endometrium is available at the time of the injury. Breast feeding mothers do not have "available" endometrium. "Endometriosis" with accompanying injuries to pelvic autonomic nerves, may result in a surprisingly wide range of clinical consequences. These include "pain in response to light touch", sensitization of central nervous system, hyperplasia of the endometrium and myometrium, and, narrowing of adjacent myometrial arterioles resulting in pregnancy complications. Concurrent, or contiguous, injuries at other levels of the sympathetic chain may result in hypertension, inflammatory bowel disease, thyroid dysfunction, Sjogren's syndrome and other "autoimmune" diseases.
\end{abstract}

Re-framing the condition as an injury to pelvic autonomic nerves with widespread, neurologic consequences consequences, may be a more appropriate, clinical framework than attributing such wide-ranging symptoms to isolated deposits of "ectopic endometrium"?

\section{Introduction}

What is the primary evidence that ectopic endometrium causes cyclic, premenstrual pain? In Figure 1a there is $1160 \mathrm{~g}$ of ectopic endometrium in a painless uterus. In Figure $1 \mathrm{~b}$ there is $260 \mathrm{~g}$ of ectopic endometrium with intrauterine bleeding from every surface of the specimen - again, in a painless uterus. Yet, we are asked to believe that a single spot of ectopic endometrium is sufficient to confine its nulliparous owner to one week in bed with chronic pelvic pain, every month (Figure 1c)? And, the asymmetric injuries to the uterosacral ligaments are unrelated to the condition (Figure 1d)? In our submission, there is no evidence that ectopic endometrium, of itself, causes cyclic, premenstrual pain. So, what causes pain, bleeding and infertility in $10 \%$ of the female population, or, $30-50 \%$ of women with pain and infertility [1-3]? In this account, difficult first labours [4], straining on the toilet [5] and gynecologic procedures [6], particularly complications of medical and surgical evacuation, cause injuries to uterotubal nerves (Figure 1, Table 1). These injuries cause uterotubal dysperistalsis with retrograde menstruation of endometrium, with-attaching to sites of tissue injury in the pelvis $[7,8]$.

In his original 1921 account, JA Sampson recorded "increasing constipation" in $3 / 23$ patients with the condition, and, a number had previous difficult deliveries [9]. Indeed, his remarks are entirely consistent with injuries to pelvic nerves causing pelvic neuropathic pain

"Twelve of the 17 symptomatic patients sought relief for pain, three for increasing constipation, and one each for uterine bleeding and sterility. The amount of pain and abnormal bleeding were quite variable, and often absent. Sampson concluded: "It is very difficult to decide whether or not these cysts cause profuse or irregular (too frequent) menstruation." As for pelvic pain, he concluded that "there is usually nothing characteristic about the pain present in this condition nor is there necessarily any relation between the extent of the adhesions and the severity of the pain."

\section{Pathogenesis of chronic, neuropathic, pelvic pain}

In simple, pathogenetic terms, injuries to uterotubal nerves result in (1) uterotubal dysmotility that results, in turn, in retrograde menstruation with ectopic endometrium (2) attaching to different injuries in the pelvis creating different laparoscopic appearances (or phenotypes (Figure 2) [2-4]. Much of the clinical confusion has resulted from (i) the dichotomous appearances of symmetric and asymmetric appearances of "deep endometriosis" (Figure 2c-d), (ii) the presence of chronic pelvic pain in women without evidence of ectopic endometrium [10]. Such phenotypes may be resolved by a thoughtful surgeon asking "What caused these injuries?" rather than "Where is

*Correspondence to: MJ Quinn, MD, LLM, Dept OBGYN, Shanghai Jiao Tong University, International Peace Maternal and Child Health Hospital, 910 Hengshan Road, Xujiahui, Shanghai, CHINA, PR 200030, E-mail: mjquinn001@ icloud.com

XU Hong, MD, Dept OBGYN, Shanghai Jiao Tong University, International Peace Maternal and Child Health Hospital, 910 Hengshan Road, Xujiahui, Shanghai, CHINA, PR 200030, E-mail: xuhong169@126.com

Received: August 20, 2019; Accepted: August 28, 2019; Published: August 30, 2019 


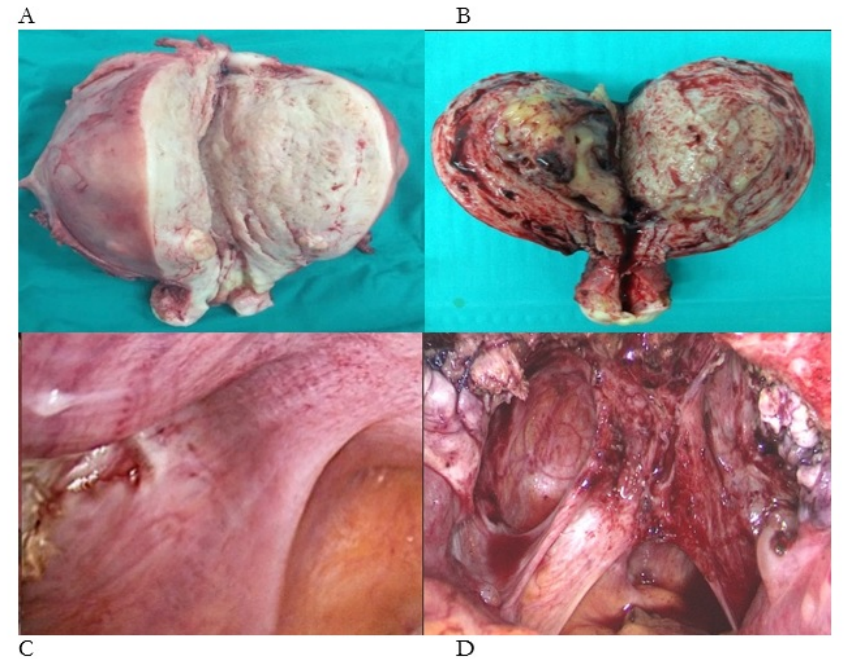

Figure 1. Photographs of four phenotypes of endometriosis-adenomyosis. (A) $1160 \mathrm{~g}$ of painless adenomyosis, (B) 260g of painless adenomyosis, (C) single deposit of endometriosis on the anterior border of the right uterosacral ligament, (D) "deep" endometriosis with large volumes of ectopic endometrium attached to injured uterosacral ligaments containing large numbers of injured uterotubal nerves with extensive neovascularisation of peritoneal surfaces
A

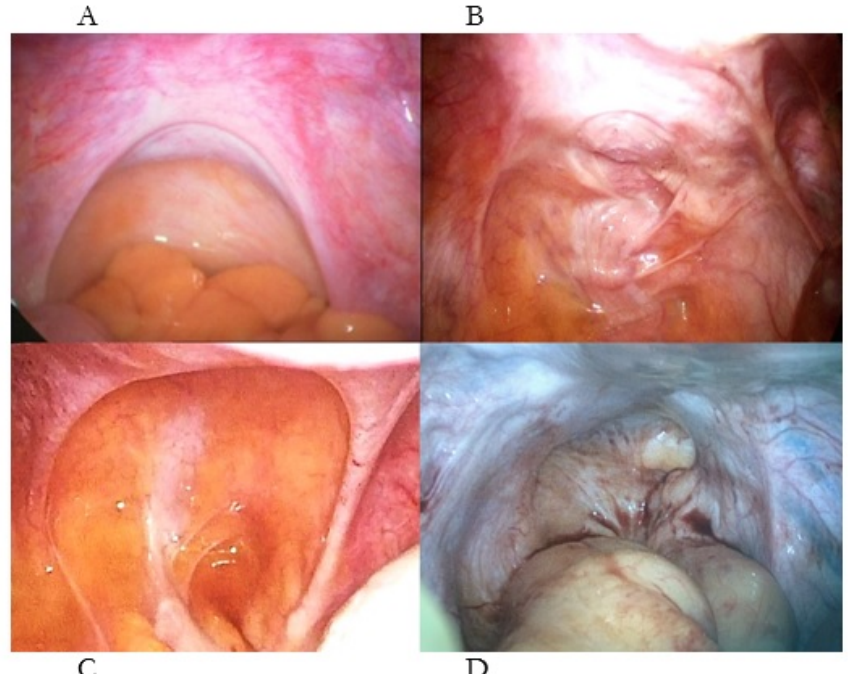

C
D
Figure 2. Different patterns of injury to the uterosacral ligaments and their contained uterotubal nerves presenting a chronic pelvic pain $(B, C)$ without "endometriosis". Complete loss of uterine nerves (D) is painless. (A) Normal uterosacral ligaments, (B) asymmetric injuries to the uterosacral ligaments following surgical abortion, (C) symmetrical attenuation of the uterosacral ligaments following medical abortion, (D) complete loss of all uterosacral tissue following medical and surgical abortions

the endometriosis ?". One key confusion has been the dichotomous, laparoscopic appearances of stage IV, nulliparous "endometriosis" and stage IV, multiparous, "endometriosis". In the former, the surgeon observes a pelvis full of ectopic endometrium but in the young, nulliparous woman it is almost always caused by straining on the toilet where the uterosacral ligaments are hypertrophic and symmetric, and, the treatment is better diet and and bowel habits [2-4]. In the older, multiparous women the uterosacral ligaments are thin, attenuated and asymmetric because she sustained her injuries during a "difficult" first labor [6]. The extent of the visible, ectopic endometrium may depend on whether she breast-fed (no ectopic endometrium) or she bottle-fed her baby (major ectopic endometrium) [2,3].
Not that we need to perform diagnostic laparoscopy [11] since asking three questions in a thoughtful, precise manner will provide most of the answers to the sources of chronic pelvic pain (Table 1)? Additional ultrasound [12] or MR imaging [13,14] will tell you if there is concurrent adenomyosis and what form that takes (Table 2) since there are distinguishable patterns of adenomyosis and leiomyoma, that are often concurrent with "endometriosis" [15,16]. Injuries to uterotubal nerves result in tubal dysmotility in some forms of infertility that are best dealt with by ART since surgery to endometriomas will reduce ovarian reserve [17]. Endometriomas (-OMA) may be examples of retrograde ectopic endometrium adhering to monthly ovarian "tissue injuries" where ovulatory follicles leave substantial areas of tissue injury that may form OMA-s without any significant contributing neural injuries, beyond that causing the "retrograde menstruation" [18]. They are painless. Extrapelvic "endometriosis" is another matter though the usual sites e.g Caesarean section scar, episiotomy, hip fractures, lung, etc are typically associated with prior injury [18]. In these presentations the pain coincides with the onset of menstruation whereas in pelvic "endometriosis" the pain usually precedes, and then improves, with the

Table 1. Three questions to ascertain the source of chronic pelvic pain caused by injuries to pelvic autonomic nerves. Positive findings with any sequence of questions should be confirmed by asking when the pain started ? There is usually a 3-5 year "neuroproliferative" interval between the injury and clinical presentation that enables sufficient neural density to cause "hyperalgesiae" or "allodyniae" ("pain or discomfort in response to light touch")

\section{(1) Bowel habits}

(a) How are your bowels?

(b) Do you go to the toilet once per day, once per week, or once per month?

(c) Do you strain, or, use physical efforts to open your bowels?

(2) First labors

(a) Were there any difficulties in your first labor?

(induced, prolonged, excessive uterine activity, fetal weight $>4000 \mathrm{~g}$,

malpresentations, operative vaginal delivery, etc all double the risk of "severe" pelvic pain at 47 months postpartum)

(b) When did the pain start?

(In a one-child family, pain starts typically, at 4-5 years postpartum; in a two child family, pain starts typically $7-8$ years after first baby)

(3) Other gynecologic procedures

(a) Have you had any other pregnancies (miscarriages or terminations)?

(b) How were they managed? (medical or surgical procedures)

(c) Did you suffer any complications? (uterine tachysystole, re-evacuation, etc)

Table 2. The "Shanghai system" of classification of adenomyosis describes injuries to nerves at different anatomic sites and subsequent development of different patterns of adenomyosis (29, Types 1-3). The full spectrum of adenomyosis is best observed in China where, typically, different injuries during gynecologic surgery lead to the later development of adenomyosis. Injuries to nerves in myomas were originally described by Savitskii (5759) and "endometriosis" by Atwal (4). All three major gynecologic pathologies may derive from neural injuries at different anatomic sites.

\section{Type 1 Diffuse, symmetric, painless adenomyosis}

This woman presents with the effects of a mass on her pelvic organs in her 30-40's e.g frequency passing urine or constipation. There is complete avulsion of the uterosacral ligaments (and uterotubal nerves) usually by surgical management of second trimester abortions. There are no nerves in the uterus or Fallopian tubes. The uterus weighs from $250-1250 \mathrm{~g}$.

\section{Type 2 Irregular, asymmetric, painful adenomyosis}

The woman presents with painful periods in her $30-40$ 's. There is a partial injury to the uterosacral ligaments combined with over-vigorous curettage of the endometrial cavity. There is aberrant reinnervation around the endometrial glands at the endometrialmyometrial interface. The uterus weighs from $80-150 \mathrm{~g}$

\section{Type 3 Focal, asymmetric, adenomyoma}

The woman presents with localized pain, or, the effects of a pelvic mass on adjacent organs in her 30-40's. There is a focal injury to the uterotubal nerves in the uterosacral ligaments with some torn nerve fibers that may lead to reinnervation, or, the enlarging tumor may "stretch" as it enlarges, resulting in localized pain. There is loss of nerve fibers in adjacent myometrial nerve bundles. The uterus weighs $100-500 \mathrm{~g}$.

Type 4 Embryologic, or unusual, adenomyosis

Embryologic remnants or unusual patterns of pedunculated, polypoid adenomyosis may contribute to this category of adenomyosis. 
onset of bleeding. Eventually, bleeding on to reinnervated peritoneal surfaces may contribute to, and extend, the duration of pain [19].

Another clinical feature suggesting the neuropathic origins of the condition are the very distressing, clinical presentations of women in their 60-70's with recurrent, chronic pelvic pain [20]. Typically, they had a "difficult" first labor in their 20's, had an early hysterectomy, experienced a decade of relief around their menopause only to be investigated by multiple clinical departments because of "new-onset" of pelvic pain in their 60-70's. These women are immensely relieved by your diagnosis of neuropathic pelvic pain on the basis of a detailed clinical history as it saves them further investigations by gastroenterologists, urologists, radiologists and pain teams, who are justifiably concerned about this de novo, clinical presentation.

\section{Causes of chronic, neuropathic, pelvic pain}

Any traumatic injury to the pelvis may cause injuries to pelvic autonomic nerves though there are three common sources of injury: these are "constipation", childbirth and gynaecologic surgery where a volsellum is applied to the cervix, followed by traction e.g. evacuation of the uterus $[2,3]$. Affected pelvic organs include the isthmus of the uterus, cervix, and vagina as well as the uterosacral-ligament complex i.e all those anatomic structures at the junction of the uterus and cervix. Although Fallopian tube, bladder, urethra, and rectum, and, their ligamentary supports may also be affected by neuropathic injuries in different shapes of pelvis with different patterns of straining [21-24].

\section{“Constipation"}

The word "constipation" means different things to different people [25]. In this context it means physical efforts to start or finish, defecation, which afflicted 20-30\% of an urban, UK population in 1993 [26]. Expulsive efforts with open sphincters lead to injuries to pelvic (and other) autonomic nerves depending on the nature and pattern of straining. The consequence is perivascular nerve fiber proliferation (PVNFP), where there are multiple layers of abnormal, injured nerves around small arterioles [27] (Figure 3e) that leads to a wide range of clinical consequences (Table 3). Dilating arterioles in the second half of the menstrual cycle cause "pain in response to light touch" (hyperalgesiae, or, allodyniae)

\section{Childbirth}

"Difficult" (induced) first labors that result in prolonged, augmented, first and second stages, or, result in the malpresentation of a $4000 \mathrm{~g}$ baby that requires operative vaginal delivery, are a potent source of pelvic autonomic neuropathy $[3,28]$. The histologic pattern is much more chaotic with widespread "collateral sprouting" of nerve bundles (Figure $3 \mathrm{~d}$ ), that is pathognomonic for prior traumatic injury.
Again, increasing blood flow in the second half of the menstrual cycle causes "pain in response to light touch" along with a wide range of other consequences.

\section{Gynecologic surgery}

Applying a volsellum to the cervix followed by traction, has the potential to cause wide-ranging injuries to pelvic autonomic nerves from complete avulsion of the uterosacral ligaments (and all uterotubal nerves) that leads to diffuse, symmetric, painless adenomyosis, to, loss of individual nerve fibers that create the conditions for myometrial denervation and development of myomas at different sites in the uterus [29] (Table 2).

\section{Consequences of chronic, neuropathic, pelvic pain (Table 3)}

There are a surprisingly wide range of clinical consequences of injuries to pelvic autonomic nerves (Table 3 ). These have been discussed in previous articles $[2,3]$. This account provides a neuroetiologic framework to explain many of the clinical "associations" of "endometriosis" that are the subject of many recent contributions to the literature.

\section{Specific clinical "associations" of endometriosis}

There are a wide range of clinical associations of "endometriosis" that have emerged in the past decade, that do not have any apparent explanation. We offer a neuro-etiologic framework to explain these phenomena.

\section{Adverse obstetric outcomes}

In a meta-analysis in 2017, Zullo [30] records "higher risks of preterm birth (OR 1.63), miscarriage (OR 1.75); placenta praevia (OR 3.03); small-for-gestational-age babies (OR 1.27), Caesarean delivery (OR 1.57), though no change in the incidence for gestational hypertension or preeclampsia. Many authors note the increased risk of the "great" obstetric syndromes in women with the classic DixonRobertson-Brosens lesion that was initially observed in the placental bed by AT Hertig, 1945 [31-33] (Figure 3e-f). We note a similar lesion in the "great" gynecologic syndromes where instead of a "halo of hyalinization" (Figure 3f) there is a "halo of injured nerves" (Figure 3e) [34,35]. It has been proposed that both result from injuries to uterine nerves. The "halo of injured nerves" is the "classic" injury in chronic pelvic pain with, or without, "endometriosis" leading to severe, premenstrual, cyclic pain - the clinical hallmark of "severe endometriosis". In our submission these histologic appearances in both "classic" obstetric and gynecologic syndromes arise from denervatory injuries to the

Table 3. Some, wide-ranging, pathologic consequences of pelvic autonomic denervation-reinnervation around the body

1) Tissue hyperplasia. Endometrial hyperplasia (myoma), myometrial hyperplasia (adenomyosis), cervical hyperplasia are consequences of estrogen-dependent hyperplasia.

2) Tissue hypoplasia. In non-estrogen -dependent tissues there is atrophy of denervated tissues e.g. bladder, bowel, vagina, vulva, etc.

3) Loss of visceral function. Early pregnancy loss, loss of cervical function in labor (cervix will not dilate), or at hysteroscopy (cervix will not open easily).

4) Loss of visceral motility. Dyspolar uterine and tubal motility leads to infertility, retrograde menstruation, and, dysfunctional labor.

5) Opportunist infection. E.coli in preterm labor, vulvovaginal Candidiasis, bacterial vaginosis in gynecology.

6) Pain. Reinnervation leads to "pain in response to light touch" (hyperalgesia or allodyniae) e.g. dysmenorrhea, vulvovaginal pain, "mesh" pain, etc

7) CNS sensitization. Interstitial cystitis, chronic pain syndromes, postmenopausal pain, chronic vulval pain, etc

8) Induction of purinergic. "stretch" receptors as secondary mechanisms of intercellular communication e.g. preeclampsia, etc

9) Viscero-visceral reflexes the uterorenal reflex leads to activation of a corticomedullary vascular "shunt" in preeclampsia. Associated with wider activation of the autonomic nervous system including headache, migraines, nausea, vomiting, restlessness, fatigue, etc

10) Ischemia-thrombosis Injuries to visceral vasomotor nerves cause narrowing of arterioles through secondary hyperplasia of the denervated arteriole. Pregnancy complications including placental abruption and placental infarction may result from narrowing of visceral arterioles. 
A

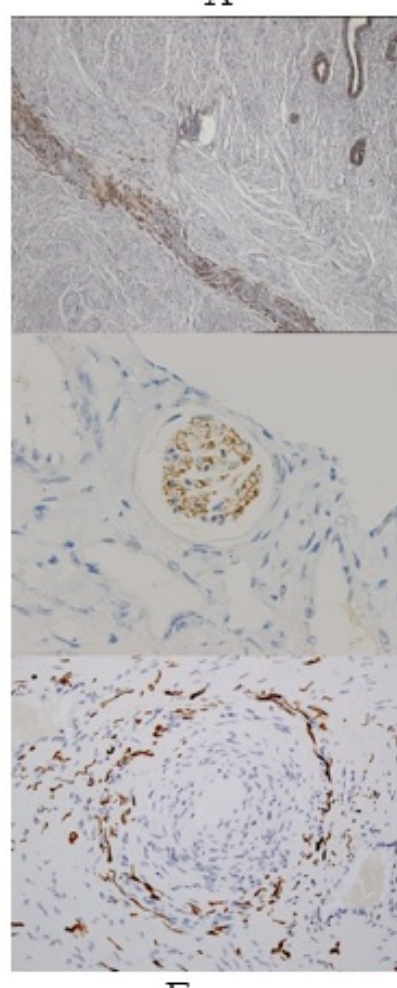

$\mathrm{E}$
B

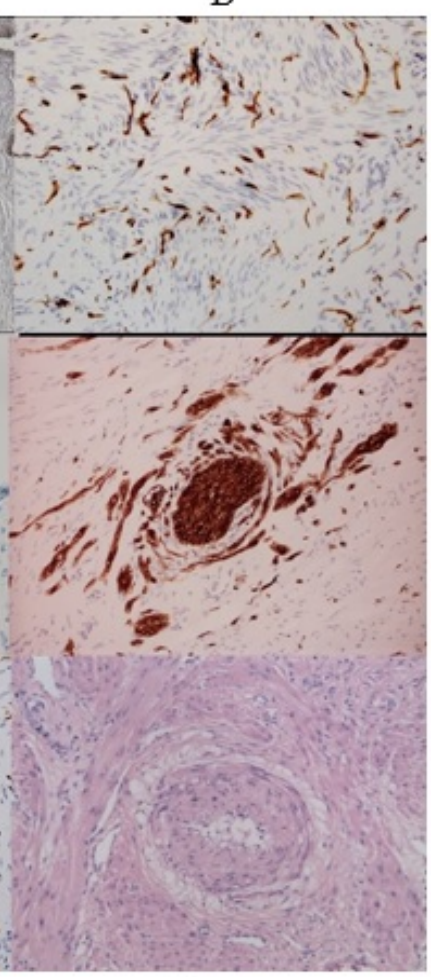

$\mathrm{F}$

Figure 3 (A-F). Neuro-immunohistochemical features of "endometriosis-adenomyosis". (A) The endometrial-myometrial nerve plexus of Krantz is injured in different patterns of adenomyosis. (B) Widespread aberrant reinnervation in the uterine isthmus, cervix, uterosacral ligaments and vagina, cause symptoms of pain and bleeding in "endometriosis". (C) Loss of uterotubal nerves in myometrial nerve bundles are diagnostic of a "pre-uterine", neural injury. (D) "Collateral sprouting" of a nerve bundle is pathognomonic of a prior traumatic injury to the nerve bundle that may contribute to impaired uterotubal function and infertility. (E) Perivascular nerve fiber proliferation around a narrowed uterine arteriole ("halo of injured nerves") creates conditions for premenstrual pain. (F) Perivascular "halo of hyalinization" in a pregnant uterus (The Dixon-Robertson-Brosens lesion) results from injuries to uterine nerves (Fig. 3e) though in pregnancy the nerves do not extend to the placental bed; their sheaths create the "halo of hyalinization". All of the "great" obstetric and gynecologic syndromes derive from injuries to the uterine nerves

uterus with their wide-ranging consequences (Table 3). It is therefore no surprise that women with this pattern of "endometriosis" have adverse pregnancy outcomes compared to controls. The "surprise" in these observations, is that women with "endometriosis". do not appear to suffer excessive rates of pre-eclampsia [30].

\section{Inflammatory bowel disease}

The small and large bowel receive innervation from adjacent sympathetic segments (T8-9) to the uterus (T10-L2) and, may develop contiguous injuries at different levels of the sympathetic chain [36] (Figure 4). Both patterns of inflammatory bowel disease demonstrate neural abnormalities though there are no accounts in the literature of patterns of neural injury in the mesentery of affected bowel. We know that mice with loperamide-induced constipation develop a condition that is histologically indistinguishable from ulcerative colitis [37]. These observations raise the concern that contiguous injuries at T8-9, may be an extension of uterine injuries (T10-L2) e.g. through different patterns of "constipation", leading to the co-presentations of inflammatory bowel disease and "endometriosis" [27].

\section{Hypertension and coronary artery disease}

In, 116,430 women in the Nurses Health Study (1989-2009), the relative risk of combined patterns of coronary heart disease was 3.08 in women aged less than 40 years [38]. That risk increased across the age range if hysterectomy and oophorectomy had been performed. The uterus and kidneys are supplied from the same sympathetic segments (T10-L2) so that any injury to the innervation to the uterus, may also result in injury to the innervation of the kidney including its vasomotor nerves. We already know that widespread visceral arteriolar narrowing in hypertension [39] arises from injuries to vasomotor nerves resulting from stress, hyperglycemia and persistent physical efforts during defecation $[40,41]$.

\section{Extrapelvic symptoms and "endometriosis"}

It is a common clinical observation that women with chronic pelvic pain with, or without, "endometriosis" present with a range of extrapelvic symptoms that include headache, nausea, vomiting, fatigue, lassitude, etc particularly when they are experiencing pelvic symptoms [42]. Similar clinical presentations are a feature of chronic pelvic pain in pregnancy between 16 weeks and delivery, often mislabeled as "symphysis-pubis dysfunction" where the weight of the gravid uterus on prior, mature pelvic injuries often characterised by avulsion of the levator ani from its origin over obturator internus [43]. They cause intense pain throughout pregnancy (Table 4).

KJ Franklin described viscero-visceral reflexes [44] where there are direct autonomic connections of one viscus with another, and more generally, where irritation of peritoneal surfaces has marked

Table 4. Strategies for improving contemporary clinical care of women with chronic pelvic pain with, or without, "endometriosis". Recognizing the lifelong consequences of injuries to pelvic autonomic nerves is an important first step in managing chronic pelvic pain. Prevention is a necessary strategy that should form an integral part of our clinical practice

1) Take a subtle, and precise, clinical history regarding injuries to pelvic autonomic nerves related to constipation, childbirth and gynecologic surgery. Avoid physical examination; it is painful, non-productive, and, you are going to have a (life)long relationship with this woman.

2) Use radiological techniques e.g. TVS /MRI to establish the presence or absence of "-OMAs" and adenomyosis. Recognise and respond to the different types of adenomyosis (Shanghai system, types I-III (29).

3) Provide advice regarding diet, bowel habits and exercise where appropriate. Enable strategies for pain relief, reducing pelvic blood flow and mood management Recognise wide-ranging extrapelvic symptoms, risk of hypertension, IBD, etc.(35, $37,41,44)$

4) IVF is an appropriate technique to bypass uterotubal nerve injuries though it will have profound consequences for obstetric outcomes since the uterotubal neurologic injuries that caused the infertility, also contribute to adverse obstetric outcomes.

5) Consider preparatory endometrial ablation to improve Mirena IUS retention rates in women with chronic pelvic pain associated with type 2 adenomyosis, in women who have completed their reproductive careers.

6) Surgery eg TAH and BSO is palliative; it is neither definitive nor curative in the context of pelvic neuropathic pain. Recurrence rates are high.

7) Recognise postmenopausal pain promptly, and, explain appropriately to provide reassurance and avoid unnecessary investigations.

8) Prevent injuries to women on your labour ward. "Neuroprotective" intrapartum care avoids induction of nulliparous labor, excessive uterine activity, prolonged labors, "difficult" operative vaginal delivery, prioritises Ventouse over forceps, etc.

9) Prevent injuries to women in our gynecologic services by avoiding excessive traction to the cervix, or, over -vigorous curettage, or, other forms of surgical excision e.g LEEP/LLETZ

10) Avoid using the term "endometriosis". It is largely an epiphenomenon to underlying injuries to pelvic autonomic nerves $(2,3)$. Wider injuries to the sympathetic division of the autonomic nervous system may be responsible for many other important, clinical associations e.g. inflammatory bowel disease, hypertension, "autoimmune disease". etc $(35,37,44)$ 


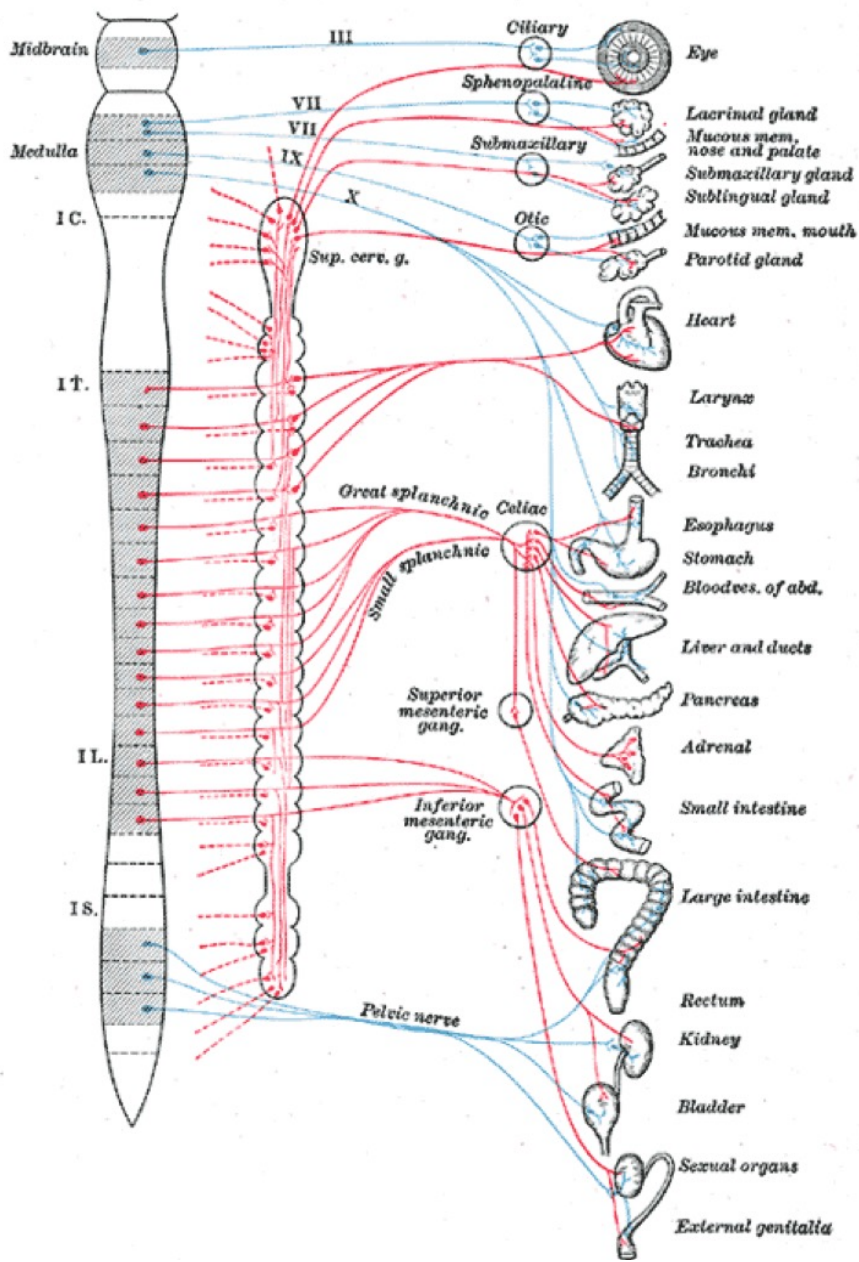

Figure 4. Sympathetic chains arise from T1-L2. Injuries to pelvic nerves may have wideranging consequences that may include cervical sympathetic nerves and the thoracolumbar chain to account for many of the "unexplained" clinical associations of "endometriosis"

physiologic effects. More recently there has been considerable interest in viscero-visceral hyperalgesia in different pain models specifically in relation to painful pelvic symptoms typical of "endoemtriosis" $[45,46]$. Extrapelvic symptoms may best be understood as being triggered by the prior pelvic injury in chronic pelvic pain resulting in all kinds of sympathetic and vagal reflexes depending on the site, nature and extent of the initial pelvic injury.

\section{“Autoimmune" diseases}

In this 2019 meta-analysis [47], this group confirm "an increased co-morbidity of autoimmune diseases including SLE, SS, RA, thyroid disorders, coeliac disease, multiple sclerosis, inflammatory bowel disease, and Addisons disease" in women with "endometriosis" though the evidence for these associations is "weak" [46]. Since the Seattle group described an "early, marked, sustained and islet-selective" loss of sympathetic nerves in bottle-fed babies [48], and, an accompanying rat model in type 1 diabetes mellitus [49], there has been the hypothesis that "autoimmune" disease is primarily a matter of autonomic denervation with the autoantibodies being secondary to the primary, neural injury [50]. If physical efforts during defecation play a role in stage IV, nulliparous "endometriosis" then there is the risk that similar physical efforts may also injure sequential endocrine glands though this should only be a "weak" association. Temporary, postpartum "autoimmune" disorders may also reflect the short term impact of a difficult, second stage of labor $[51,52]$ ?

Though the evidence is variable, there is a plausible relationship between women with chronic pelvic pain with, or without, "endometriosis" and wider injuries through varying mechanisms to the sympathetic nervous system that may explain these otherwise inexplicable associations. These provide additional weight to the neuro-etiologic framework for chronic pelvic pain with, or without, "endometriosis".

\section{Achieving neuro-etiologic "causation"}

Clearly the neuro-etiologic associations of endometriosisadenomyosis-myoma may be bolstered by an appropriate, animal model. Most animals do not eat low-fiber diets, and, do not have difficulties with their bowel habits or vaginal deliveries, By necessity any such model will be contrived to some extent. "Endometriosis" may be created in baboons by ligation of the cervix $[53,54]$ though this is simply an obstructive pattern of "endometriosis" that does not engage neuro-etiologic injuries. One, recent suggestion has been to administer loperamide (an anti-diarrhoeal agent) to mice, we know this creates a condition analogous to ulcerative colitis and inflammatory bowel disease in the four-legged posture [37,55]. Any animal model needs to reflect the etiology of the condition where possible. It is not surprising it has been difficult to achieve this in "endometriosis" given the efficiency that most animals have concerning their diets, bowel habits, and reproductive capacity.

Even without an animal model there is increasing evidence for neuro-etiologic injuries in "endometriosis", adenomyosis and leiomyoma [56]. Savitskii noted the absence of nerves in leiomyoma though we observe loss of nerves in adjacent nerve bundles together with leashes of injured arterioles adjacent to small myomas [57-59]. Many colleagues have reported neural injuries in "endometriosisadenomyosis" [60-71] though undoubtedly the most entertaining has been the suggestion that injuries to nerve bundles in the cervix are "induced" by deposits of ectopic endometrium [72]. Any textbook of pathology explains that "collateral sprouting of nerve bundles" is pathognomonic for prior traumatic injury; deposits of ectopic endometrium do not cause traumatic injuries? Our group has already explained a potential classification of four types of adenomyosis based on different types of neuro-etiologic injury sustained during gynecologic surgery, or, in childbirth, with evidence for the site of the neurologic injury [29] (Table 2).

\section{Conclusion}

The etiology of "endometriosis" has become a matter of "religious" belief. You either believe that deposits of ectopic endometrium cause cyclic, premenstrual pain, or, you are prepared to contemplate a neurologic explanation. In our submission, "endometriosis" may best be regarded as a lifelong injury to the pelvic autonomic system with wide-ranging consequences in other parts of the body through a series of varying, neuro-pathologic mechanisms. Deposits of ectopic endometrium are largely epiphenomena to underlying injuries to pelvic nerves. This account offers a framework of autonomic denervation-reinnervation that may better explain many of the causes and consequences of "endometriosis". Notably, there is a clinical explanation for many of the "remote" clinical associations of "endometriosis" that have been described in the past decade e.g. extrapelvic manifestations, inflammatory bowel disease, "autoimmune" disease, and, hypertension. 
Stepping into this "new" paradigm provides a comprehensible, etiologic explanation that is a great relief to many women, even though they have to contemplate a lifetime of neuropathic pain. It avoids many surgical interventions. Prevention of iatrogenic injury takes on greater significance as we struggle with the complexity of contemporary intrapartum management that is not "neuroprotective" in any sense of the word. High rates of nulliparous inductions of labor promote maternal "neuropathic" injuries. Simply understanding the potential consequences of applying a volsellum to the anterior lip of the cervix should be sufficient to concern most gynecologists ? The essential "shift" is not to move to a "clinical" paradigm as suggested by recent "calls to action" [1], but it is to embrace a full, neurologic re-wiring of our specialty ? This will enable an improved understanding of many other pelvic neuropathic pain syndromes e.g. irritative bladder, urethral syndrome, "mesh" syndromes, irritable bowel syndromes, cervical denervation-reinnervation and its consequences in labor, ectopic pregnancy, abdominal pain in parous pregnancy, as well as many of the "great" obstetric syndromes including pre-eclampsia [73,74]. It is surprising how satisfying a single step from empiric chaos into a coherent framework can be?

\section{References}

1. Agarwal SK, Chapron C, Giudice LC, Laufer MR, Leyland N, et al. (2019) Clinical diagnosis of endometriosis: a call to action. Am J Obstet Gynecol 220: 354. [Crossref]

2. Quinn M (2009) Endometriosis: the elusive epiphenomenon. J Obstet Gynaecol 29: 590-593. [Crossref]

3. Quinn MJ (2011) Endometriosis: the consequence of uterine denervation-reinnervation. Arch Gynecol Obstet 284: 1423-9. [Crossref]

4. Atwal G, du Plessis D, Armstrong G, Slade R, Quinn M (2005) Uterine innervation after hysterectomy for chronic pelvic pain with, and without, endometriosis. $A m J$ Obstet Gynecol 193:1650-5. [Crossref]

5. Quinn MJ (2007) Perivascular nerve fibre proliferation: the consequence of prolonged straining. J Obstet Gynaecol 27: 185-8. [Crossref]

6. Quinn M, Kirk N (2004) Uterosacral nerve fibre proliferation in parous endometriosis. J Obstet Gynaecol 24: 189-90. [Crossref]

7. Kissler S, Zangos S, Wiegratz I, Kohl J, Rody A, et al. (2007) Utero-tubal sperm transport and its impairment in endometriosis and adenomyosis. Ann N Y Acad Sci 1101: 38-48. [Crossref]

8. Kissler S, Hamscho N, Zangos S, Wiegratz I, Schlichter S, et al. (2006) Uterotubal transport disorder in adenomyosis and endometriosis--a cause for infertility. BJOG 113: 902-908. [Crossref]

9. Sampson JA (1921) Perforating hemorrhagic ("chocolate") cysts of the ovary. Their importance and especially their relation to pelvic adenomas of endometrial type. Adenomyoma of the uterus, rectovaginal septum, sigmoid, etc. Arch Surg 3:245-323.

10. Quinn MJ (2011) Origins of 'deep infiltrating endometriosis'. BJOG 118: 1142-1143. [Crossref]

11. Chapron C, Lafay-Pillet MC, Monceau E, Borghese B, Ngô C, et al. (2011) Questioning patients about their adolescent history can identify markers associated with deep infiltrating endometriosis. Fertil Steril 95: 877-881. [Crossref]

12. Dumontier I, Roseau G, Vincent B, Chapron C, Dousset B, et al. (2000) Comparison of endoscopic ultrasound and magnetic resonance imaging in severe pelvic endometriosis. Gastroenterol Clin Biol 24: 1197-1204.

13. Kinkel K, Chapron C, Balleyguier C, Fritel X, Dubuisson JB, et al. (1999) Magnetic resonance imaging characteristics of deep endometriosis. Hum Reprod 14: 1080-1086. [Crossref]

14. Kishi Y, Suginami H, Kuramori R, Yabuta M, Suginami R, et al. (2012) Four subtypes of adenomyosis assessed by magnetic resonance imaging and their specification. Am J Obstet Gynecol 207: 114.e1-7. [Crossref]

15. Bazot M, Daraï E (2018) Role of transvaginal sonography and magnetic resonance imaging in the diagnosis of uterine adenomyosis. Fertil Steril 109: 389-397. [Crossref]

16. Kitajima M, Khan KN, Harada A, Taniguchi K, Inoue T, et al. (2018) Association between ovarian endometrioma and ovarian reserve. Front Biosci (Elite Ed) 10: 92102. [Crossref]
17. Matalliotakis M, Goulielmos GN, Kalogiannidis I, Koumantakis G, Matalliotakis I, et al. (2017) Extra pelvic endometriosis: Retrospective analysis on 200 cases in two different countries. Eur J Obstet Gynecol Reprod Biol 217: 34-37. [Crossref]

18. Wang G, Tokushige N, Fraser IS (2011) Nerve fibers and menstrual cycle in peritoneal endometriosis. Fertil Steril 95: 2772-2774. [Crossref]

19. Valentini AL, Gui B, Basilico R, Di Molfetta IV, Miccò M, et al. (2012) Magnetic resonance imaging in women with pelvic pain from gynaecological causes: a pictorial review. Radiol Med 117: 575-592. [Crossref]

20. Quinn MJ (2008) Endometrial nerve fiber proliferation in "endometriosis". Am J Obstet Gynecol 199: e13. [Crossref]

21. Quinn MJ, Slade RJ, Armstrong G (2006) Vaginal vault reinnervation and symptoms of genital prolapse. J Obstet Gynaecol 26: 177-178. [Crossref]

22. Quinn M, Slack M, Kirk N, Harris M (2002) Obstetric denervation, gynecologic reinnervation. Am J Obstet Gynecol 186: 168. [Crossref]

23. Quinn M (2001) Reinnervation after childbirth--a new paradigm for sensory bowel symptoms? Gut 49: 597-598. [Crossref]

24. Probert CS, Emmett PM, Cripps HA, Heaton KW (1994) Evidence for the ambiguity of the term constipation: the role of irritable bowel syndrome. Gut 35: 1455-1458. [Crossref]

25. Heaton KW, Cripps HA (1993) Straining at stool and laxative taking in an English population. Dig Dis Sci 38: 1004-1008. [Crossref]

26. Quinn MJ (2007) Perivascular nerve fibre proliferation: the consequence of prolonged straining. J Obstet Gynaecol 27: 185-188. [Crossref]

27. Golding J (1990) Children of the nineties. A longitudinal study of pregnancy and childhood based on the population of Avon (ALSPAC). West England Med J 105: 8082. [Crossref]

28. Zhang LN, Chen L, Hong X, Wang Y, Zhang HJ, et al. (2019) Neuro-etiologic classification of adenomyosis: the "Shanghai system". Clin Obstet Gynecol Reprod Med.

29. Zullo F, Spagnolo E, Saccone G, Acunzo M, Xodo S, et al. (2017) Endometriosis and obstetrics complications: a systematic review and meta-analysis. Fertil Steril 108: 667672. [Crossref]

30. Hertig AT (1945) In: Kellogg FS (Eds) “Toxemias of Pregnancy” 4: 602-613.

31. De Wolf F, Brosens I, Renaer M (1980) Fetal growth retardation and the maternal arterial supply of the human placenta in the absence of sustained hypertension. $\mathrm{Br} \mathrm{J}$ Obstet Gynaecol 87: 678-685. [Crossref]

32. Brosens IA (1977) Morphological changes in the utero-placental bed in pregnancy hypertension. Clin Obstet Gynaecol 4: 573-593. [Crossref]

33. Quinn MJ (2016) The aetiology of narrowed uterine arterioles in obstetric and gynaecological syndromes. Placenta 44: 114. [Crossref]

34. Quinn M (2006) Sustained constipation and subsequent reproductive outcomes: is there a link? J Obstet Gynaecol 26: 366-367. [Crossref]

35. Jess T, Frisch M, Jørgensen KT, Pedersen BV, Nielsen NM (2012) Increased risk of inflammatory bowel disease in women with endometriosis: a nationwide Danish cohort study. Gut 61: 1279-1283. [Crossref]

36. Kim JE, Go J, Sung JE, Lee HA, Yun WB, et al. (2017) Uridine stimulates laxative effect in the loperamide-induced constipation of SD rats through regulation of the $\mathrm{mAChRs}$ signaling pathway and mucin secretion. BMC Gastroenterol 17: 21. [Crossref]

37. Mu F, Rich-Edwards J, Rimm EB, Spiegelman D, Missmer SA (2016) Endometriosis and Risk of Coronary Heart Disease. Circ Cardiovasc Qual Outcomes 9: 257-264. [Crossref]

38. Moritz AR, Oldt MR (1937) Arteriolar Sclerosis in Hypertensive and Non-Hypertensive Individuals. Am J Pathol 13: 679-728. [Crossref]

39. Li YY, Gu QR, Chen GR, Quinn MJ (2018) Arteriolar Injury in Hypertension. Am J Med 131: e133-e134.

40. Gu QR, Li YY, Chen GR, Quinn MJ (2018) The arteriolar injury in hypertension. Med Hypotheses 111: 66-69. [Crossref]

41. Smorgick N, As-Sanie S (2018) Pelvic Pain in Adolescents. Semin Reprod Med 36 116-122. [Crossref]

42. Quinn M (2007) Injuries to the levator ani in unexplained, chronic pelvic pain. J Obstet Gynaecol 27: 828-831. [Crossref] 
43. Franklin KJ (1962) The utero-renal reflex: the haemex phenomenon. J Obstet Gynaecol Br Emp 69: 506-507. [Crossref]

44. Brinkert W, Dimcevski G, Arendt-Nielsen L, Drewes AM, Wilder-Smith OH, et al. (2007) Dysmenorrhoea is associated with hypersensitivity in the sigmoid colon and rectum. Pain 132: S46-51. [Crossref]

45. Berkley KJ, Cason A, Jacobs H, Bradshaw H, Wood E, et al. (2001) Vaginal hyperalgesia in a rat model of endometriosis. Neurosci Lett 306: 185-188. [Crossref]

46. Shigesi N, Rahmioglu N, Kvaskoff M, Feng Q, Fang H, et al. (2017) A systematic review of the association between endometriosis and autoimmune diseases. PROSPERO International prospective register of systematic reviews.

47. Mundinger TO, Mei Q, Foulis AK, Fligner CL, Hull RL, et al. (2016) Human Type 1 Diabetes Is Characterized by an Early, Marked, Sustained, and Islet-Selective Loss of Sympathetic Nerves. Diabetes 65: 2322-2330. [Crossref]

48. Taborsky GJ Jr, Mei Q, Hackney DJ, Figlewicz DP, LeBoeuf R, et al. (2009) Loss of islet sympathetic nerves and impairment of glucagon secretion in the NOD mouse: relationship to invasive insulitis. Diabetologia 52: 2602-2611. [Crossref]

49. Quinn M (2008) "Autoimmune" conditions and autonomic denervation. Am J Med 121: e13. [Crossref]

50. Di Bari F, Granese R, Le Donne M, Vita R, Benvenga S (2017) Autoimmune Abnormalities of Postpartum Thyroid Diseases. Front Endocrinol (Lausanne) 13: 166. [Crossref]

51. Bergink V, Pop VJM, Nielsen PR, Agerbo E, Munk-Olsen T, et al (2018) Comorbidity of autoimmune thyroid disorders and psychiatric disorders during the postpartum period: a Danish nationwide register-based cohort study. Psychol Med 48: 1291-1298. [Crossref]

52. Nyachieo A, Chai DC, Deprest J, Mwenda JM, D'Hooghe TM (2007) The baboon as a research model for the study of endometrial biology, uterine receptivity and embryo implantation. Gynecol Obstet Invest 64: 149-155. [Crossref]

53. D'Hooghe TM (1997) Clinical relevance of the baboon as a model for the study of endometriosis. Fertil Steril 68: 613-625. [Crossref]

54. Kim JE, Lee MR, Park JJ, Choi JY, Song BR, et al (2018) Quercetin promotes gastrointestinal motility and mucin secretion in loperamide-induced constipation of SD rats through regulation of the mAChRs downstream signal. Pharm Biol 56: 309-317. [Crossref]

55. Vannuccini S, Petraglia F (2019) Recent advances in understanding and managing adenomyosis. F1000Res 8: 283. [Crossref]

56. Savitskiı̌ GA, Morozov VV, Svechnikova FA, Ivanova RD (1981) Pathogenesis of uterine myoma development. Akush Ginekol (Mosk) 4: 13-15.

57. Savitskiǐ GA, Skopichev VG, Rakitskaia VV (1986) "Denervation" of the tumor node as one of the elements of pathogenesis of uterine myoma. Akush Ginekol (Mosk) 2: 24-27.

58. Savitskii GA, Skopichev VG, Shelest VN (1987) The pathogenesis of uterine myomas. Vestn Akad Med Nauk SSSR 1: 62-8.
59. Wang G, Tokushige N, Fraser IS (2011) Nerve fibers and menstrual cycle in peritoneal endometriosis. Fertil Steril. 95: 2772-2774. [Crossref]

60. Wang G, Tokushige N, Russell P, Dubinovsky S, Markham R, et al. (2009) Hyperinnervation in intestinal deep infiltrating endometriosis. J Minim Invasive Gynecol 16: 713-719.

61. Tran LV, Tokushige N, Berbic M, Markham R, Fraser IS (2009) Macrophages and nerve fibres in peritoneal endometriosis. Hum Reprod 24: 835-841. [Crossref]

62. Al-Jefout M, Andreadis N, Tokushige N, Markham R, Fraser I (2007) A pilot study to evaluate the relative efficacy of endometrial biopsy and full curettage in making a diagnosis of endometriosis by the detection of endometrial nerve fibers. Am J Obstet Gynecol 197: 578.e1-4. [Crossref]

63. Tokushige N, Markham R, Russell P, Fraser IS (2008) Effects of hormonal treatment on nerve fibers in endometrium and myometrium in women with endometriosis. Fertil Steril 90: 1589-1598. [Crossref]

64. Fraser IS, Tokushige N, Markham R, Russell P (2008) Sensory nerve endings and endometriotic implants. Fertil Steril 89: 1847. [Crossref]

65. Tokushige N, Markham R, Russell P, Fraser IS (2007) Different types of small nerve fibers in eutopic endometrium and myometrium in women with endometriosis. Fertil Steril 88: 795-803. [Crossref]

66. Tokushige N, Markham R, Russell P, Fraser IS (2006) High density of small nerve fibres in the functional layer of the endometrium in women with endometriosis. Hum Reprod 21: 782-787. [Crossref]

67. Tokushige N, Markham R, Russell P, Fraser IS (2006) Nerve fibres in peritonea endometriosis. Hum Reprod 21: 3001-3007. [Crossref]

68. Ibrahim MG, Chiantera V, Frangini S, Younes S, Köhler C, et al. (2015) Ultramicrotrauma in the endometrial-myometrial junctional zone and pale cell migration in adenomyosis. Fertil Steril 104: 1475-1483.e1-3. [Crossref]

69. Barcena de Arellano ML, Oldeweme J, Arnold J, Schneider A, Mechsner S (2013) Remodeling of estrogen-dependent sympathetic nerve fibers seems to be disturbed in adenomyosis. Fertil Steril 100: 801-809. [Crossref]

70. Lu BC, Huang XF, Zhou CY, Xu H, Lin J, et al. (2009) Distribution of nerve fibers in endometrium and its clinical significance in adenomyosis. Zhonghua Fu Chan $\mathrm{Ke} \mathrm{Za}$ Zhi 44: 324-327.

71. Yunker A, Curlin H, Banet N, Fadare O, Steege J (2015) Does the uterine cervix become abnormally reinnervated after subtotal hysterectomy and what is the association with future trachelectomy? J Minim Invasive Gynecol 22: 261-267. [Crossref]

72. Brosens I, Pijnenborg R, Vercruysse L, Romero R (2011) The "Great Obstetrical Syndromes" are associated with disorders of deep placentation. Am J Obstet Gynecol 204: 193-201. [Crossref]

73. Zhou ZY, Xu XX, Wu XQ, Quinn MJ (2019) Preeclampsia: the uterine denervation view. Injuries to uterine nerves, the uterorenal reflex, and renal cortico-medullary shunt. Clin Obstet Gynecol Reprod Med 5:1-6.

74. Wu XQ, Xu XX, Zhou ZY, Quinn MJ (2019) Arteriolar injuries in clinical obstetrics and gynecologic syndromes. Clin Obstet Gynecol Reprod Med 5: 1-7.

Copyright: (2019 Bing Xin Y. This is an open-access article distributed under the terms of the Creative Commons Attribution License, which permits unrestricted use, distribution, and reproduction in any medium, provided the original author and source are credited. 